\title{
Concomitant diagnosis of primary Sjögren's syndrome and systemic AL amyloidosis
}

\author{
I Delèvaux, M André, Z Amoura, J-L Kémény, J-C Piette, O Aumaître
}

\begin{abstract}
A 48 year old woman was referred to hospital for buccal discomfort. Physical examination showed a macroglossia and features of xerostomia. She was diagnosed as having primary Sjögren's syndrome according to the criteria proposed by the European Community study group in 1993. Furthermore, a lower lip salivary gland biopsy showed amyloid deposits that were also seen in the stomach and in the bone marrow. Echocardiography was consistent with cardiac amyloidosis. Serum immunofixation identified a monoclonal IgG $\lambda$. As far as is known, this is the first report of systemic primary amyloidosis associated with Sjögren's syndrome. The relation between these two disorders is discussed.
\end{abstract}

(Ann Rheum Dis 2001;60:694-695)

Primary Sjögren's syndrome is an autoimmune disorder that exposes a patient to the development of lymphoproliferative disorders. The occurrence of amyloidosis in primary Sjögren's syndrome has rarely been reported: only a few cases of localised amyloidosis either with or without lymphoma are mentioned. We describe herein the case of a patient who presented with both primary Sjögren's syndrome and systemic $\mathrm{AL}$ amyloidosis.
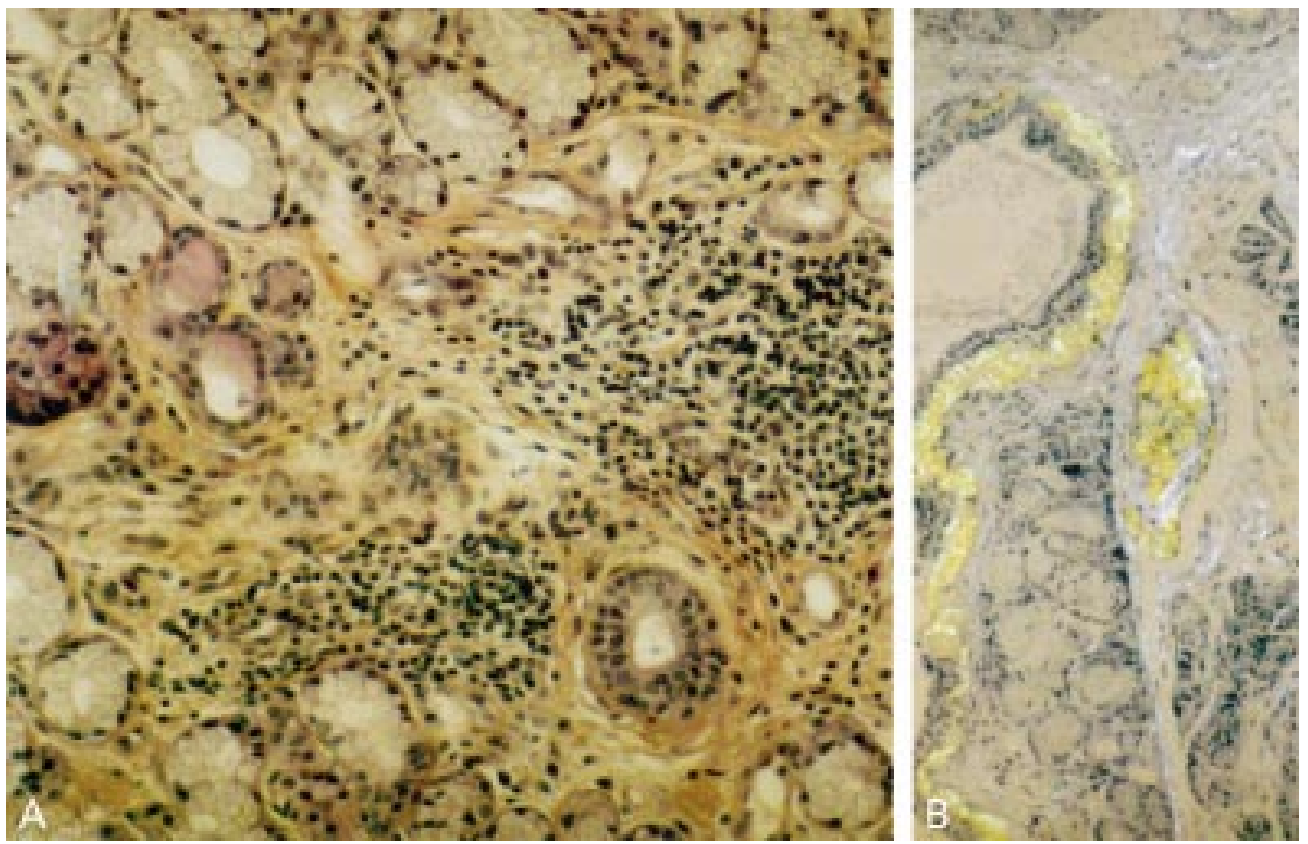

Figure 1 Labial salivary gland biopsy showing (A) two foci with more than 50 lymphocytes/mm ${ }^{2}$ (haematoxylin and eosin, original magnification $\times 80)$; (B) amyloid deposits around the salivary ducts with green birefringence under polarised light microscopy after exposure to potassium permanganate (Congo red, original magnification $\times 40$ ).

\section{Case report}

A 48 year old woman was admitted to our department for a tongue discomfort of three weeks' duration. She complained of xerostomia, xerophthalmia, and trigeminal dysaesthesia. Physical examination showed a macroglossia and mouth dryness.

Her white and red blood cell count was normal. Serum creatinine, $C$ reactive protein, thyroid stimulating hormone, and $\beta_{2}$ microglobulin were within the normal range. Serum (normal $0.85-2.7$ ), and $1.18 \mathrm{~g} / 1$ for $\operatorname{IgM}$ (normal 0.62-1.74). Serum immunofixation showed a monoclonal IgG $\lambda$. Anti-Ro/SSA antibodies were positive by enzyme linked immunosorbent assay (ELISA) (ENADOT bmd). Searches for cryoglobulin (home method) and markers for hepatitis $C$ virus were negative. ${ }^{1}$ A Schirmer test was positive and the break up time was abnormal. Histological examination of a minor salivary gland biopsy specimen (fig 1) showed an infiltration of glandular interstitium by lymphocytes and plasma cells. There were three inflammatory foci containing more than 50 cells in six lobules examined. According to the Chisholm scale, the patient had a biopsy grade 4 . There were also amorphous deposits in the interstitium and in concentrations of immunoglobulins were $23 \mathrm{~g} / 1$ for IgG (normal 6.6-12.3), $0.7 \mathrm{~g} / 1$ for $\mathrm{IgA}$
Department of Internal Medicine, G Montpied hospital, BP

Clermont-Ferrand, France

I Delèvaux

M André

O Aumaître

Department of Pathology, G Montpied hospital

J-L Kémény

Department of Internal Medicine , Pitié-Salpêtrière hospital, 47-83 boulevard de l'Hôpital, 75651 Paris cedex 13,

France

Z Amoura

J-C Piette

Correspondence to: Professor O Aumaître oaumaitre@

chu-clermontferrand.fr

Accepted 15 November 2000 
the vessel walls. After pretreatment with potassium permanganate, they were stained with Congo red and so were consistent with AL amyloid protein deposits. Immunohistochemical stains showed positive intracytoplasmic immunoreactivity of plasma cells for anti-IgG, IgM, and sometimes IgA with $\kappa$ chain restriction. Bone marrow biopsy showed $7 \%$ of normal plasma cells; Congo red staining demonstrated amyloid deposits within vessel walls. Immunohistochemical studies showed that the cytoplasm of the plasma cells was stained with anti- $\kappa$ and anti- $\lambda$ light chains and with anti-IgA heavy chain antibodies. Thoracoabdominal computed tomography (CT) was normal. Endoscopic examination of the upper gastrointestinal tract was unremarkable, but amyloid deposits were found near the fundus glands on biopsy specimens. An electromyogram was normal. An electrocardiogram showed pseudo infarct Q waves on V5 to V6 leads and echocardiography an abnormal diastolic function. No lytic bone lesion was observed on radiographs.

Systemic AL amyloidosis associated with Sjögren's syndrome was diagnosed. High dose chemotherapy with cyclophosphamide followed by autologous stem cell transplantation was given to the patient. Three months after transplantation she improved, but the gammopathy and anti-Ro/SSA antibodies persisted.

\section{Discussion}

Our patient complained of xerophthalmia and xerostomia. The diagnosis of primary Sjögren's syndrome was supported by a Schirmer test, the break up time, the positivity of anti-Ro/SSA antibodies, and the lower lip salivary gland biopsy. The presence of a macroglossia led us to search for an associated amyloidosis. The immunohistochemical examination of several tissues confirmed the presence of AL amyloid deposits. Salivary gland amyloid deposition may cause sicca syndrome, and minor salivary gland biopsy has been said to be a reliable test to diagnose amyloidosis. ${ }^{2}$ Our patient had both true primary Sjögren's syndrome and primary systemic amyloidosis. ${ }^{34}$ Amyloid deposits were found not only in the salivary gland but also in stomach and bone marrow biopsy specimens, and were probably responsible for macroglossia and heart abnormalities. An IgG $\lambda$ gammopathy was found by immunofixation, but the diagnosis of multiple myeloma was not allowed because bone marrow infiltration by plasma cells was lower than $10 \%$. A hypothetical underlying lymphoma was ruled out by normal thoracoabdominal CT scan and bone marrow biopsy.

Unlike the well known association of Sjögren's syndrome with low grade marginal zone B cell lymphoma, ${ }^{5}{ }^{6}$ the coexistence of primary amyloidosis and Sjögren's syndrome is rare. Only eight cases have been previously reported in the English literature. In all these published cases, amyloidosis was localised or limited to dermis, ${ }^{7-9}$ lung, ${ }^{10}{ }^{11}$ or tongue. ${ }^{12}$ In some cases, plasma cells were found surrounding the amyloid deposits. Monotypic or polytypic light chains, thought to be the precursors of amyloidosis, were discovered in these cells and in amyloid deposits. ${ }^{12}{ }^{13}$ In one case a localised cutaneous amyloidosis with a monoclonal gammopathy was found, but there was no multiple myeloma.

To our knowledge, primary systemic amyloidosis has not been reported so far in association with Sjögren's syndrome. One case of primary nodal plasmacytoma with Sjögren's syndrome has been described but without amyloidosis. ${ }^{14}$ Wong et al reported on a patient with secondary amyloidosis (amyloid protein AA) of the lung during Sjögren's syndrome. ${ }^{15}$

Our patient differed from these cases because of the presence of systemic amyloidosis and the slight plasma cell infiltration on bone marrow biopsy. Even if extensive investigations have not been performed in previous reports of patients with localised amyloidosis and Sjögren's syndrome, it should be noted that none of them developed systemic amyloid involvement or plasma cell proliferation.

Although a chance association cannot be firmly excluded, this case report shows that the spectrum of lymphoid proliferations associated with Sjögren's syndrome extends beyond the classical B cell lymphoma. Staining for amyloidosis should be performed in patient with Sjögren's syndrome and unexplained findings, such as a macroglossia.

1 Romaszko JP, Tridon A, Jouanel P, Subtil E, Dibet P, Betail G. Détection et analyse des cryoglobulines: étude comparative d'une population de malades et d'une population de témoins sains. Pathol Biol 1993;41:525-9.

2 Hachulla E, Janin A, Flipo RM, Saile R, Facon T, Bataille D, et al. Labial salivary gland biopsy is a reliable test for the diagnosis of primary and secondary amyloidosis. A prospective clinical and immunohistologic study in 59 patients. Arthritis Rheum 1993;36:691-7.

3 Myssiorek D, Alvi A, Bhuiya T. Primary salivary gland amyloidosis causing sicca syndrome. Ann Otol Rhinol Laryngol 1992;101:487-90.

4 Schlesinger I. Multiple myeloma and AL amyloidosis mimicking Sjögren syndrome. South Med J 1993;86:568-9.

5 Mariette X. Lymphomas in patients with Sjögren's syndrome: review of the literature and physiopathologic hypothesis. Leuk Lymphoma 1999;33:93-9.

6 Royer B, Cazals-Hatem D, Sibilia J, Agbalika F, Cayuela JM, Soussi T, et al. Lymphomas in patients with Sjögren's syndrome are marginal zone B-cell neoplasms, arise in diverse extranodal and nodal sites, and are not associated with viruses. Blood 1997;2:766-75.

7 Kitajima Y, Seno J, Aoki S, Tada S, Yaoita H. Nodular primary cutaneous amyloidosis. Arch Dermatol 1986;122: 1425-30.

8 Pablos JL, Cogolludo V, Pinedo F, Carreire PE. Subcutaneous nodular amyloidosis in Sjögren's syndrome. Scand J Rheumatol 1993;22:250-1.

9 Inazumi T, Hakuno M, Yamada $H$, Tanaka $M$, Naka W, Tajima S, et al. Characterisation of the amyloid fibril from primary localized cutaneous nodular amyloidosis associated with Sjögren's syndrome. Dermatology 1994;189: $125-8$.

10 Kobayashi H, Matsuoka R, Kitamura S, Tsunoda N, Saito K. Sjögren's syndrome with multiple bullae and pulmonary nodular amyloidosis. Chest 1988;94:438-40.

11 Milburn JM, Kay D, Ridpat C. Pulmonary nodular amyloidosis in a patient with Sjögren's syndrome diagnosed by transthoracic biopsy. J La State Med Soc 1994;146:395-8.

12 Haraguchi H, Ohashi K, Yamada M, Hasegawa M, Maeda $S$, Komatsuzaki A. Primary localized nodular tongue amyloidosis associated with Sjögren's syndrome. ORL J Otorhinolaryngol Relat Spec 1997;1:60-3.

13 Ishihara T, Takahashi M, Koga M, Yokota T, Yamashita Y, Uchino F. Amyloid fibril formation in the rough endoplasmic reticulum of plasma cells from a patient with localized $\mathrm{A} \lambda$ amyloidosis. Lab Invest 1991;64:265-71.

14 Watanabe K, Yatabe Y, Narita M, Ogawa T, Mori N. An autopsy case of primary nodal plasmocytoma associated with Sjögren's syndrome. Pathol Int 1999;49:577-9.

15 Wong BC, Wong KL, Ip MS, Wang EP, Chan KW, Cheng LC. Sjögren's syndrome with amyloid A presenting as multiple pulmonary nodules. J Rheumatol 1994;21:165-7. 